\title{
Construção da democracia, diálogo político e capital social na transição de Timor-Leste para a independência
}

Democracy-Building, Political Dialogue and Social Capital in Timor-Leste's

Transition to Independence

Construction de la démocratie, dialogue politique et capital social dans la transition du Timor-Leste vers l'indépendance

\section{Akihisa Matsuno}

Tradutor. João Paulo Galvão

\section{(2) OpenEdition Journals}

Edição electrónica

URL: http://journals.openedition.org/rccs/5709

DOI: $10.4000 /$ rccs. 5709

ISSN: 2182-7435

Editora

Centro de Estudos Sociais da Universidade de Coimbra

Edição impressa

Data de publição: 1 setembro 2014

Paginação: 83-100

ISSN: 0254-1106

Refêrencia eletrónica

Akihisa Matsuno, «Construção da democracia, diálogo político e capital social na transição de Timor-Leste para a independência », Revista Crítica de Ciências Sociais [Online], 104 | 2014, posto online no dia 23 setembro 2014, consultado o 10 dezembro 2020. URL : http://journals.openedition.org/rccs/ 5709 ; DOI : https://doi.org/10.4000/rccs.5709 


\section{AKIHISA MATSUNO}

\section{Construção da democracia, diálogo político e capital social na transição de Timor-Leste para a independência}

O artigo defende que a crise de 2006 em Timor-Leste adveio parcialmente de um processo deficiente de construção da democracia durante a administração de transição da Organização das Nações Unidas (ONU). Embora o mandato de construção da democracia fosse ambíguo, as Nações Unidas iniciaram o estabelecimento de instituições liberais com base no pressuposto, largamente consensual, de que a democracia tinha que ser firmemente estabelecida no Timor-Leste pós-conflito. Contudo, ao concentrar os seus recursos na criação de instituições estatais na capital, a administração de transição exacerbou as disparidades entre a capital e os distritos, criando um Estado forte isolado e deixando as pessoas menos capacitadas a nível das comunidades. A apressada agenda de transição também privou as elites políticas da oportunidade de um diálogo político para lidar com os aspetos mais importantes da agenda de reconciliação e não conseguiu criar as infraestruturas de apoio ao ativismo cívico para, a longo prazo, aumentar o capital social.

Palavras-chave: capital social; construção da paz; democratização do Estado; pós-guerra; Timor-Leste.

\section{Introdução}

A crise de 2006 em Timor-Leste foi uma crise política de uma democracia emergente. $\mathrm{O}$ governo não conseguiu lidar adequadamente com as queixas dos soldados. Nem a liderança militar nem o governo procuraram comunicar com o grupo de soldados descontentes ou peticionários cujo número chegara a quase 600, correspondendo a perto de metade das Forças Armadas. Em vez disso, dispensaram-nos a todos abruptamente sem considerarem as consequências de demitir um tão grande número de soldados de uma só vez. ${ }^{1}$

\footnotetext{
${ }^{1}$ No início de 2006, alguns soldados de distritos ocidentais comandados pelo Tenente Gastão Salsinha alegaram serem discriminados por comandantes dos distritos orientais. O que provocou os soldados dos distritos ocidentais foi um insulto de um comandante oriental, segundo o qual os ocidentais não eram de confiança porque não tinham combatido tanto nas lutas pela independência quanto os orientais (ICG, 2006: 6).
} 
Os líderes do país pareciam distantes e desligados das realidades que as pessoas diariamente enfrentavam. Quando a juventude frustrada se juntou aos motins e um novo grupo de rebeldes chefiado pelo comandante da polícia militar ${ }^{2}$ surgiu, os líderes de governo começaram secretamente a armar civis para defender os seus interesses. Este facto, quando foi denunciado, não só revelou a incapacidade do governo de entender o problema, mas também desacreditou de forma fatal a liderança. Rapidamente se multiplicaram os apelos à demissão do Primeiro-Ministro, mesmo até entre os membros do governo. ${ }^{3}$

Por detrás da crise estava a situação económica, política e social desde a restauração da soberania do país, ou da independência, em 2002. A economia tinha "continuado a contrair-se após a retirada do pessoal da ONU e outros colaboradores de programa de auxílio" (UNDP, 2006: 1). Os críticos alegaram que o sistema político se tinha tornado cada vez mais autoritário (Siapno, 2006) e que a rivalidade de longa data entre Xanana Gusmão e Mari Alkatiri tinha polarizado mais ainda a política (Shoesmith, 2003). Os políticos da oposição e os jornalistas sentiam-se inseguros perante as declarações desassombradas do primeiro-ministro e os ativistas da sociedade civil encontravam-se desmotivados pela indiferença geral, embora não antagónica, do governo relativamente ao ativismo cívico. A juventude educada na Indonésia sentia-se alienada pela política de língua do governo, que pretendia promover o português (Grove et al., 2007). O desemprego aumentou, e os gangs e grupos de artes marciais tinham-se tornado um problema de segurança nos subúrbios urbanos de Díli, que se encontravam em rápida expansão (Scambary, 2006).

Identificar as causas da crise e definir estratégias para abordar cada uma delas eram tarefas imediatas para a Organização das Nações Unidas (ONU) e para o Governo de Timor-Leste. Uma lição óbvia foi a necessidade de reforma do setor de segurança. O Grupo Internacional de Crise recomendou "uma revisão abrangente do papel e das necessidades futuras do setor de segurança" (ICG, 2006). No contexto da intervenção internacional, Matthew B. Arnold argumentou que "são cruciais para o setor da segurança mandatos abrangentes da ONU e/ou forças de paz internacionais" e afirmou ainda que "o timing é crucial para a tomada de ações decisivas” (2009: 447-448). A Comissão Especial Independente de Inquérito

\footnotetext{
${ }^{2}$ A 4 de maio, o comandante da polícia militar, Major Alfredo Reinado, refugiou-se nas montanhas com as suas tropas e exigiu a demissão do Primeiro-Ministro, Mari Alkatiri.

${ }^{3}$ Para uma descrição mais pormenorizada dos acontecimentos, ver o relatório da Comissão Especial Independente de Inquérito para Timor-Leste das Nações Unidas (United Nations, 2006). Kingsbury (2007) apresenta uma análise abrangente da crise e respetivas causas.
} 
para Timor-Leste das Nações Unidas "estabeleceu a responsabilidade dos diversos atores e instituições" e "fez recomendações sobre medidas de responsabilização a serem concretizadas através do sistema judicial nacional" (United Nations, 2006).

Escusado será dizer que eram necessárias medidas imediatas para combater as causas, mas é igualmente importante perguntarmo-nos o que não funcionou no processo de construção da paz em Timor-Leste. Porque a crise foi uma crise política e o sistema político naquela época tinha sido criado principalmente aquando da Administração Transitória das Nações Unidas em Timor-Leste, a UNTAET (1999-2002). O declínio democrático que os observadores testemunharam nos primeiros quatro anos de independência de Timor-Leste deve ser entendido como resultado de uma fraca construção da democracia sob a vigência da UNTAET.

Oliver Richmond e Jason Franks (2008) apresentaram uma análise abrangente do insucesso da construção da paz liberal em Timor-Leste e referem o fracasso da construção de "um contrato social entre a sociedade e suas instituições de governação" e "a legitimidade social" dos atores internacionais (2008: 186). Os autores criticaram ainda o sequestro dos processos de democratização pela Fretilin como representando um fracasso dos atores internacionais e das elites de Timor-Leste a quem os primeiros "concederam autoridade para contornar a democracia através da marginalização de outros atores e da instituição de um regime de partido único" (ibidem: 194). Os meus dois artigos anteriores analisaram os problemas da construção da democracia, especialmente as fraquezas do enquadramento e das políticas institucionais durante a UNTAET (Matsuno, 2008 e 2009). Referi o desequilíbrio derivado do Estado e da criação de instituições centrada na capital, as disposições constitucionais que permitiram o autoritarismo e a falta de transparência do processo decisório. Este artigo visa trazer mais um pequeno contributo para o debate sobre a construção da democracia em Timor-Leste, chamando especialmente a atenção para a necessidade de interação de três atores na construção da democracia: os peacebuilders internacionais, as elites políticas nacionais e a sociedade civil. O artigo incide sobre o período da Administração Transitória de 1999 a 2002, a fim de identificar mais especificamente alguns dos problemas da construção da democracia nesse período. É claro que os fatores que subjazem à crise de 2006 não se limitam àqueles que tiveram origem nesse período e é fácil encontrar mais causas imediatas da crise no período pós-independência de 2002 a 2006. Existe uma série de análises destas causas mais imediatas, incluindo a minha própria (2009), mas talvez se justifique o estreitamento do foco, uma vez que as origens dos fatores 
estruturais que levaram à crise foram estabelecidas basicamente no período da Administração Provisória.

\section{O quadro ambíguo da UNTAET}

Ninguém nega a importância da construção da democracia em sociedades pós-conflito. Juntamente com a segurança, o Estado de direito, os direitos humanos e a governação, a democracia faz parte, e muito corretamente, do vocabulário essencial da construção da paz, e torna-se particularmente importante quando um novo Estado independente está a ser criado numa sociedade que não tem a experiência prévia de um regime democrático. Defendo que sem democracia é difícil conseguir uma estabilidade política durável, a qual é o objetivo último de todos os projetos de construção da paz.

No entanto, a construção da democracia parece ser a área de atuação menos desenvolvida. A democracia no contexto da construção da paz foi mencionada pela primeira vez em An Agenda for Peace (Uma Agenda para a Paz), de Boutros Ghali (A/47/277-S/24111, 1992), embora o conceito tivesse mais a ver com direitos humanos e não tanto com instituições e dispositivos políticos. Pode ler-se no parágrafo 81 que a democracia exige "respeito pelos direitos humanos e pelas liberdades fundamentais", "bem como uma mais profunda compreensão e respeito pelos direitos das minorias e o respeito pelas necessidades dos grupos mais vulneráveis da sociedade, especialmente as mulheres e as crianças". A Cimeira Mundial de 2005 reafirmou que "a democracia é um valor universal que se baseia na vontade livremente expressa das pessoas de determinar os seus próprios sistemas políticos, económicos, sociais e culturais e a sua plena participação em todos os aspetos das suas vidas". ${ }^{4}$ Depois disso, as Nações Unidas iniciaram a tradução da sua retórica em ações concretas. A Nota de Orientação do Secretário-Geral das Nações Unidas sobre Democracia (2007) enumera oito domínios de intervenção nos quais a ONU tem uma vantagem comparativa: (1) facilitação política; (2) participação popular e eleições livres e justas; (3) cultura da democracia; (4) pluralismo político; (5) transparência e responsabilização; (6) Estado de direito; (7) governação inclusiva e com capacidade de resposta; e (8) uma sociedade civil dinâmica. O Fundo das Nações Unidas para a Democracia (UNDEF) iniciou o financiamento em 2007 e, todos os anos, 50 a 60 projetos da sociedade civil são selecionados para financiamentos de valor entre 50000 e 400000 dólares. ${ }^{5}$ Em geral,

\footnotetext{
${ }_{4} 2005$ World Summit Outcome. A/RES/60/1, 24 de outubro de 2005, parágrafo 135.

5 Ver a página web do Fundo das Nações Unidas para a Democracia (UNDEF). Até agora o UNDEF financiou quatro organizações em Timor-Leste: Sindicato dos Jornalistas de Timor Lorosa'e (SJTL), PNUD, Rede Feto (Rede Mulher) e o Programa de Monitorização do Sistema Judicial (JSMP).
} 
entendemos que, entre os governos do mundo, há agora um vago consenso sobre democracia, definida de forma ambígua, e a ONU dá apoio a projetos da sociedade civil, embora pareça existir pouco envolvimento direto com as instituições fundamentais do Estado.

Em 1999, a UNTAET funcionava num quadro muito mais ambíguo. Além disso, a construção da democracia não era explicitamente referida no mandato da UNTAET. A Resolução 1272 (25 de outubro de 1999) do Conselho de Segurança sobre a UNTAET referia como elementos do mandato, entre outros, "garantir a segurança e manter a lei e a ordem", "estabelecer uma administração eficaz" e "apoiar a criação de competências para a autogovernação". Quando comparada com a Resolução 1244 (10 de junho de 1999) do Conselho de Segurança sobre a Missão de Administração Interina das Nações Unidas no Kosovo (UNMIK), que incluía a criação e supervisão de "desenvolvimento de instituições provisórias de autogoverno democrático" (ênfase do autor), a ausência do atributo "democrático" referente ao autogoverno na Resolução sobre a UNTAET é curiosa.

No entanto, penso que tanto na comunidade internacional como entre os timorenses havia um amplo consenso relativamente à necessidade de se estabelecer com firmeza uma democracia em Timor-Leste independente. Mas que tipo de democracia teriam em mente, uma vez que o país não tinha uma história de experiências democráticas? Como observador que visitava frequentemente Timor-Leste na época pós-referendo, julgo que, pelo menos, as pessoas em geral consideravam a Indonésia da Nova Ordem ou o regime de Suharto como um mau exemplo. Para a maioria dos timorenses que haviam experimentado diretamente a ocupação indonésia, o sistema de governo indonésio era um sinónimo de corrupção, arrogância e arbitrariedade. Parecia que as pessoas tinham a ingénua esperança de virem a ter um governo limpo e preocupado com as pessoas, líderes dedicados e funcionários públicos esforçados.

Pairava um ponto de interrogação sobre o conceito de democracia da Fretilin. Em 1975, a Fretilin procurava um sistema de partido único e, após a invasão da Indonésia, radicalizou-se mais ainda, acabando numa luta interna mortal a propósito de ideologias e estratégias. Mais tarde, a Fretilin aderiu ao Concelho Nacional da Resistência Maubere (CNRM, que se tornou Conselho Nacional da Resistência Timorense - CNRT em 1999), uma organização unificada para a independência sob a liderança do nacionalista moderado Xanana Gusmão. Mas visto que a Fretilin nunca discutiu publicamente o seu passado sombrio, permanecia uma dúvida sobre as suas credenciais democráticas.

O que a UNTAET pensava sobre a construção da democracia em Timor-Leste também não era muito claro. A democracia não ocupava um lugar importante no discurso da $\mathrm{ONU}$ sobre os preparativos para a independência. 
A sua perspetiva sobre esses preparativos enquadrava-se num contexto mais tecnocrático que colocava a prioridade na criação de diversas instituições de Estado nos setores administrativo, judiciário, de segurança e do serviço social. ${ }^{6}$ E esses preparativos tinham de ser concluídos com as restrições existentes de tempo, orçamento e recursos humanos. Havia alguns projetos de educação cívica, mas que preconizavam a democracia em termos muito gerais. Apesar de toda esta ambiguidade, é talvez possível dizer que existia um amplo entendimento segundo o qual a democracia deveria significar um sistema multipartidário liberal com a divisão de poderes entre o legislativo, o executivo e o judiciário.

Os preparativos políticos começaram muito tarde, em julho de 2001, dezoito meses após o início da missão, com o processo eleitoral para a Assembleia Constituinte. E foi nessa campanha eleitoral de seis semanas que a velha rivalidade veio à superfície. A afirmação perentória da Fretilin de que tinha sido ela quem defendera a independência durante vinte e quatro anos, aliada à simpatia geral dos eleitores pela Fretilin como partido histórico que sacrificara tanto para a libertação do país, resultou na sua vitória esmagadora. ${ }^{7}$ A Assembleia Constituinte, dominada pela Fretilin, elaborou uma constituição mais favorável ao partido por via do enfraquecimento dos poderes tanto do Presidente como do Parlamento. Quando, em março de 2002, a Assembleia Constituinte decidiu manter-se como Assembleia Nacional, a Fretilin conseguiu garantir o seu domínio por mais cinco anos.

Richmond e Franks argumentam que, devido à pressão de Nova Iorque para o estabelecimento de uma democracia e um governo que funcionassem, a UNTAET organizou eleições de forma algo apressada, antes mesmo de se terem criado instituições políticas eficazes. "O resultado foi a consolidação da Fretilin numa posição de poder sem par” (Richmond e Franks, 2008: 192-193). Retrospetivamente, pode-se dizer que a ONU tinha subestimado a gravidade dos problemas políticos internos dos timorenses e o seu impacto sobre os processos democráticos pós-referendo que geria. É realmente irónico, como escrevem Richmond e Franks, "mesmo sob a orientação da ONU, os processos de democratização (em Timor-Leste) foram sequestrados" (ibidem: 193).

\section{Desenvolvimento institucional Dili-cêntrico}

A construção do Estado levada a cabo pela UNTAET centrou-se, como seria de esperar, em Díli. Historicamente, Díli foi construída como um posto

\footnotetext{
${ }^{6}$ Ver os vários Relatórios de Progresso do Secretário-Geral sobre a Missão das Nações Unidas em Timor-Leste entre dezembro 1999 e abril 2002.

${ }^{7}$ Fui observador eleitoral internacional acreditado nas eleições para a Assembleia Constituinte.
} 
colonial português, isolado da sociedade agrária feudal de Timor-Leste. Posteriormente, a Indonésia tornou Díli o centro de políticas de segurança e de desenvolvimento do regime ocupante. Durante ambos os períodos, Díli não conseguiu incorporar nem desenvolver o território (Moxham, 2008: 7). Nenhum dos regimes foi capaz de desenvolver um sistema político representativo de baixo para cima que fizesse chegar ao centro as vozes locais. A construção do Estado centrada em Díli sob a UNTAET exacerbou o isolamento político de Díli e a relação de cima para baixo entre Díli e os distritos.

A UNTAET estabeleceu os ramos executivo, legislativo e judiciário do governo e criou a burocracia, a Polícia e as Forças Armadas. Tomou também decisões sobre os princípios básicos da política para áreas importantes como finanças, segurança e gestão de recursos minerais - tudo em conformidade com o mandato que detinha para "estabelecer uma administração eficaz”. Mas estas instituições faziam parte do governo central e, naturalmente, concentraram-se em Díli. Também as agências da ONU, os governos estrangeiros, as organizações internacionais e as organizações não governamentais $(\mathrm{ONG})$ tinham os seus gabinetes e representações sobretudo em Díli. A UNTAET estabeleceu gabinetes para os administradores de distrito, mas sem qualquer objetivo de representar a população local, apesar de os administradores terem relações de trabalho com os líderes locais através, por exemplo, da antiga organização de resistência CNRT. ${ }^{8}$

Para cerca de $85 \%$ da população, que vivia fora da capital (UNDP, 2002: 13), isso significava que não existia praticamente nenhuma instituição ou nenhum mecanismo que pudesse canalizar as suas necessidades locais de forma a fazê-las chegar às autoridades centrais. Esta situação deixou as pessoas dependentes de ligações pessoais, tais como laços de família ou redes clandestinas, para fazer ouvir as suas exigências.

O crescimento rápido de Díli foi trazido pelo boom da economia durante o período da UNTAET. A população de Díli em 1995 era de 157460 pessoas, incluindo possivelmente dezenas de milhares de indonésios (Pedersen e Aneberg, 1999: 180). Na sequência do caos pós-referendo em setembro de 1999, quase toda a população de Díli fugiu para as montanhas ou foi deportada para Timor Ocidental. Quando, em 2001, foi realizado um inquérito à população, a população de Díli tinha recuperado, somando

\footnotetext{
${ }^{8}$ O CNRT (Conselho Nacional da Resistência Timorense) foi formado oficialmente em 1999, mas o seu predecessor, o CNRM, tinha sido formado em 1988. Quase todas as organizações da resistência faziam parte do CNRT e, na ocasião do referendo, o Conselho Nacional da Resistência Timorense tornou-se o candidato oficial da área pró-independência. Entende-se que o CNRT esperasse ser visto como a organização representativa dos timorenses no período de transição, mas a ONU demorou alguns meses a perceber essa expectativa.
} 
então 120474 pessoas (Suco Survey, 2001) e quando o primeiro censo foi realizado, em 2004, aquele número tinha aumentado para 167777 (Projeções Populacionais 2004-2050). A taxa de crescimento entre 2001 e 2004 foi de $39,4 \%$, o que indica que as oportunidades económicas de Díli sob a administração da UNTAET atraíram muitos imigrantes dos distritos. O facto de a ONU não ter sido capaz de travar a concessão de poder a uma Díli já privilegiada tornou os distritos ainda mais dependentes do centro.

Enquanto isso, havia um subinvestimento nas instituições locais. A UNTAET atribuiu um orçamento para o governo subnacional pela primeira vez no seu Fundo Consolidado de Timor-Leste (FCTL) de 2001-2002. Foram atribuídos 2 milhões de dólares, ou seja, 30000 por subdistrito, correspondendo apenas a 1,94\% do orçamento total de 103,3 milhões de dólares (Matsuno, 2008: 54). Ao contrário do Kosovo, as eleições locais não foram realizadas sob a administração das Nações Unidas. Quando a UNTAET deixou Timor em 2002, havia apenas uma hierarquia administrativa de cima para baixo, da capital até à aldeia, e não se elegeram chefes administrativos nem conselhos locais. Foi só em 2004 que a lei sobre eleições dos Chefes de Suco (aldeia) e dos Conselhos de Suco e o decreto-lei sobre autoridades comunitárias foram anunciados. As primeiras eleições para os Conselhos de Suco decorreram durante vários meses, de 2004 a 2005.

Se as eleições locais deveriam ser realizadas antes das nacionais ou não continua a ser tema de debate. No Kosovo, a ONU decidiu realizar as eleições municipais em primeiro lugar, não apenas porque as eleições nacionais não eram ainda viáveis devido à incerteza sobre o estatuto final do Kosovo, mas também porque a realização de eleições nacionais foi "considerada como não mais do que uma parte do processo de desenvolvimento institucional a longo prazo" (Cogen e de Brabandere, 2007: 678). Larry Diamond refere-se à realização precoce de eleições locais antes das nacionais como uma das sete lições aprendidas no Iraque. O autor argumenta que "é muito lógica a realização prévia de eleições locais" (2005: 20). Esta daria aos líderes locais não só uma oportunidade para ganhar experiência, mas também lhes concederia legitimidade como representantes do povo perante as autoridades centrais.

Em Timor-Leste, o Banco Mundial realizou um projeto muito interessante chamado Projeto de Capacitação Comunitária (Community Empowerment Project-CEP). O CEP financiou mais de 1000 projetos comunitários, num total de 2,5 milhões de dólares. Cada aldeia recebeu uma quantia média de 5000 dólares para os projetos de desenvolvimento que a população desejasse. Para decidir o que construir ou comprar, estabeleceram-se conselhos de desenvolvimento da aldeia. Os conselhos incluíam pelo menos 
dois representantes de cada aldeia democraticamente escolhidos, com um número igual de homens e mulheres. A conceção do CEP era suficientemente democrática, mas enquanto exercício de construção da democracia teve apenas um efeito limitado. Os conselhos foram criados somente para lidar com os fundos de desenvolvimento e nada mais. Os líderes locais e tradicionais foram especificamente proibidos de serem membros do conselho. O processo foi concebido para dar transparência e fomentar responsabilização relativamente aos projetos, e não para resolver questões políticas ou discutir estratégias de desenvolvimento comunitário de longo prazo.

\section{Falta de diálogo político}

A crise de 2006, conforme foi explicado acima, revelou que a rivalidade entre Xanana Gusmão e Mari Alkatiri, ou, mais amplamente, a rivalidade entre o grupo de Unidade Nacional e a Fretilin, tinha ficado por resolver. Essa rivalidade não era segredo, mas creio que muitas pessoas não poderiam prever que levaria a uma batalha tão feroz. Até agora não existe certeza de que o problema tenha sido resolvido com a vitória do grupo de Xanana Gusmão no final da crise e nas duas eleições legislativas subsequentes, de 2007 e 2012. Essencialmente, nada ficou resolvido.

Por conseguinte, o que pretendemos perceber é como devem os problemas políticos internos ser tratados no contexto da construção da democracia ou da construção da paz. Deve a solução desses problemas ser deixada aos líderes políticos locais por si sós ou devem os peacebuilders externos adotar uma abordagem mais intervencionista? No caso de Timor-Leste, a primeira abordagem revelou-se ineficaz. Contudo, antes de avançarmos para a segunda hipótese, será útil vermos que medidas foram disponibilizadas às elites políticas de Timor-Leste durante a Administração Transitória.

A forma como a UNTAET poderia tomar em consideração as vozes dos timorenses não era clara no início porque o mapa político de Timor-Leste ainda estava a ser desenhado e a política timorense encontrava-se num processo de rápida transformação. Inicialmente, Sérgio Vieira de Mello, Representante Especial do Secretário-Geral (RESG) e Chefe da Missão, da UNTAET, tratou Xanana Gusmão como líder de facto do país ${ }^{9}$ e, consequentemente, o seu círculo como parceiros de diálogo timorenses da UNTAET no momento. Mas esta opção preocupava os líderes da Fretilin que nem sempre haviam apoiado Xanana Gusmão como o único líder da

\footnotetext{
9 Sérgio Vieira de Mello disse a Samantha Power que tinha de imediato corrido para Xanana Gusmão pelo facto de o comparar ao Príncipe Sihanouk do Camboja. Vieira de Mello tinha trabalhado para a UNTAC - Autoridade de Transição das Nações Unidas no Camboja (Power, 2008).
} 
resistência e viria daí em diante a tornar-se uma fonte de relações menos fáceis entre a UNTAET e a Fretilin.

A primeira medida que a UNTAET tomou para melhorar a participação timorense na administração provisória foi a criação do Conselho Consultivo Nacional (CCN). Sérgio Vieira de Mello chegou a Timor-Leste a 16 de novembro e, após conversações com alguns líderes timorenses, foi criado o CCN através do Regulamento n. ${ }^{\circ} 2 / 1999$, de 2 de dezembro. O Conselho era composto por 15 membros: quatro funcionários da UNTAET, incluindo o RESG como Presidente; sete do CNRT, incluindo Xanana Gusmão; três dos grupos políticos exteriores ao CNRT; e um da Igreja Católica. Os grupos políticos para além do CNRT eram a BRTT (Frente Popular de Timor-Leste), o PNT (Partido Nacionalista Timorense) e o FPDK (Fórum para a Unidade, Democracia e Justiça). A BRTT e o FPDK eram grupos pró-autonomia. O PNT era liderado por Abílio Araújo, um ex-chefe deposto da delegação externa da Fretilin baseada em Lisboa.

Xanana Gusmão, que tinha chegado a Timor-Leste em 22 de outubro, ficou frustrado pelo modo como a UNTAET tratava o CNRT. Numa entrevista, queixou-se de que a UNTAET tinha ocupado todos os melhores edifícios, enquanto o CNRT, que tinha obtido $78,5 \%$ dos votos no referendo de agosto, estava com dificuldades para encontrar uma sede. Xanana Gusmão também propôs que fossem nomeados timorenses para cargos na UNTAET, enquanto os funcionários internacionais deveriam apenas preencher as lacunas. ${ }^{10}$ Mais tarde, Xanana foi também citado por Samantha Power como tendo afirmado: "nós sentimos que estávamos a ser usados. Percebemos que não estávamos lá para ajudar a ONU a tomar decisões ou para nos prepararmos para gerir a administração. Nós estávamos lá para carimbar os regulamentos do Sérgio de Mello, para permitir que a ONU afirmasse a sua função de aconselhamento" (Power, 2008: 307). Não é que a ONU não soubesse das graves rivalidades internas entre as elites de Timor-Leste. Um professor de ciência política, Vicente Faria, que mais tarde se tornaria membro do parlamento eleito pela Fretilin, terá comentado: "Agora o verdadeiro inimigo está cá dentro. Temos muitas fações e interesses rivais, e devemos reconciliá-los. É esse o desafio político que enfrentamos". ${ }^{11}$ A ONU pensou que era demasiado cedo para o povo de Timor-Leste formar grupos políticos e tentou adiar para uma fase posterior

\footnotetext{
${ }_{10}$ Asiaweek, 3 de dezembro de 1999: “'The U.N. is Not Listening' - Xanana Gusmão on East Timor's Present and Future” (“'As Nações Unidas não estão a ouvir' - Xanana Gusmão falando sobre o presente e o futuro de Timor-Leste").

${ }^{11}$ International Herald Tribune, 16 de dezembro de 1999, "Timorese Factions Are Key to Nationhood" ("As fações timorenses são essenciais para o sentimento de nação").
} 
o surgimento de competição política. Na minha opinião, foi um erro ver a rivalidade interna dos timorenses meramente como uma competição política normal entre partidos políticos em qualquer parte do mundo. Tratava-se de uma questão de sacrifício, honra e legitimidade. A História era uma questão de vida ou morte para eles e as feridas históricas tinham ainda de ser curadas. Como afirmou Vicente Faria, a "reconciliação" era o desafio político que enfrentavam.

Contudo, não havia nenhum fórum para lidar com esse desafio. O CCN era totalmente inapropriado, e naquela época a UNTAET em geral dava muito pouca atenção às questões substanciais relacionadas com a construção da nação. Durante a sua visita a Timor-Leste, em meados de janeiro de 2000, o ministro dos Negócios Estrangeiros da Nova Zelândia, Phil Goff, comentou: "a menos que passemos rapidamente à organização da infraestrutura física e das instituições democráticas fundamentais (ênfase minha), haverá enormes problemas sociais". ${ }^{12}$

Em 14 de julho de 2000, após consulta intensiva, a UNTAET decidiu substituir o CCN por um novo organismo, mais amplo e quasi-legislativo, o Conselho Nacional (CN). O CN foi criado em 23 de outubro, tendo sido projetado para poder acolher uma participação mais ampla e mais elevada dos timorenses na tomada de decisões. O número de membros aumentou para 36 e foi permitido ao Conselho escolher entre os seus membros um presidente, que definiria a agenda e conduziria as sessões. Os membros foram nomeados por Sérgio Vieira de Mello: um de cada um dos 13 distritos, 13 dos partidos políticos, incluindo os antigos grupos pró-autonomia, e um representante de cada um dos seguintes grupos: juventude, organizações não-governamentais, grupos de mulheres, organizações profissionais, agricultores, trabalhadores, empresas, igreja católica, igreja protestante e comunidade muçulmana. Xanana Gusmão foi eleito presidente e Milena Pires vice-presidente.

Em paralelo com o estabelecimento do CN, a UNTAET criou o Governo Transitório de Timor-Leste (GTTL) em agosto de 2000, a fim de transferir gradualmente a autoridade administrativa da ONU para o povo de Timor-Leste. O GTTL funcionava sob a UNTAET e tinha nove ministérios, estando cinco das pastas sob a responsabilidade de timorenses: Negócios Estrangeiros, José Ramos Horta; Administração Interna, Ana Pessoa; Infraestruturas, João Carrascalão; Assuntos Económicos, Mari Alkatiri; e Assuntos Sociais, Filomeno Jacob. Havia também cargos para inspeção,

${ }_{12}$ The Press, 14 de janeiro de 2000, "Rebuilding in East Timor 'Urgent"” ("Reconstrução em Timor-Leste "Urgente”"). 
defesa e planeamento ocupados por timorenses: Mariano Lopes, Roque Rodrigues e Emília Pires, respetivamente.

Desde o início, o executivo e o legislativo foram concebidos como instituições separadas sem interações significativas. $\mathrm{O} C \mathrm{CN}$ afinal não constituía uma legislatura, e tinha um poder diminuto relativamente à Administração. Além disso, à exceção de Xanana, os líderes políticos mais proeminentes de Timor-Leste nessa altura não eram membros do $\mathrm{CN}$, mas procuraram posições no GTTL. Esta situação tornou o $\mathrm{CN}$ num veículo pouco atraente para os políticos.

A criação do CN e do GTTL ocorreu quando o CNRT se desintegrava em fações políticas. O primeiro congresso do CNRT pós-referendo foi realizado em agosto de 2000, mas a respetiva comissão organizadora tinha tido pouca participação, o que levou Xanana Gusmão a reclamar da aparente falta de interesse. ${ }^{13}$ No Congresso, Xanana Gusmão e os seus companheiros mais próximos monopolizaram os cargos mais altos, diluindo significativamente a influência da Fretilin e da União Democrática Timorense (UDT). Então, a Fretilin e a UDT praticamente deixaram o CNRT, boicotando o seu Conselho Permanente.

A competição entre os grupos políticos tornou-se cada vez mais acesa. De outubro de 2000 a março de 2001, o CN debateu o enquadramento das eleições para a Assembleia Constituinte. As eleições foram realizadas em agosto de 2001, e todas as áreas da Constituição foram objeto de intensa discussão na Assembleia. Quando a Constituição foi aprovada pela Assembleia Constituinte, em 22 de março de 2002, pouco tempo sobrou para os grupos políticos discutirem outras questões. Em abril, realizaram-se eleições presidenciais, e em maio foi anunciada a restauração da soberania.

Em retrospetiva, pensamos que o que faltou neste processo foi o diálogo político entre os líderes e também entre as pessoas, sobre a história da sua luta, a qual estava cheia de controvérsias. Entre os graves problemas do passado contavam-se em especial o golpe de agosto de 1975 da UDT, que desencadeara a guerra civil e ajudara a criar um pretexto para a invasão indonésia, as execuções de prisioneiros da UDT e Apodeti (Associação Popular Democrática Timorense) pela Fretilin, em Aileu, após a invasão, e a purga daqueles que haviam sugerido a rendição à Indonésia, nas montanhas, no final de 1970. Embora a UNTAET não tivesse nada a ver com a questão do passado, julgo que, para que a construção da paz fosse significativa em Timor-Leste, esta questão deveria ter sido discutida. Possivelmente, Francis Fukuyama tinha

${ }_{13}$ Lusa, 2 de agosto 2000, “Gusmão: E Timor Not Ready for Democracy, Independence?” (Gusmão: Timor-Leste não está preparado para a Democracia, Independência?”). 
razão ao escrever que Timor-Leste não foi capaz de criar um sentido de unidade nacional ou de uma identidade subjacente que pudesse servir de travão às ambições de líderes individuais e de fações políticas (Fukuyama, 2006).

Em dezembro de 2013, a Comissão de Acolhimento, Verdade e Reconciliação (CAVR) realizou uma audição pública de quatro dias sobre o conflito político. ${ }^{14} \mathrm{~A}$ audição tinha sido originalmente agendada para julho, mas a Comissão e os vários partidos demoraram muito mais tempo do que o esperado a chegar a acordos aceitáveis relativamente à sua organização. $\mathrm{Na}$ audição, Xanana Gusmão, Mari Alkatiri, José Ramos Horta, Rogério Lobato, Francisco Xavier do Amaral, Moniz Maia e Tomás Gonçalves falaram sobre as respetivas experiências e opiniões. Foi a primeira vez que o povo timorense ouviu as opiniões dos seus líderes sobre o difícil problema do passado expressas publicamente e de forma direta. Mas é óbvio que o tempo não foi suficiente, e houve muito pouca interação entre os líderes. No final da audição, alguns líderes abraçaram-se e a plateia aplaudiu com entusiasmo. Contudo, como se veio a verificar depois, a encenação não significou muito em termos de reconciliação entre as fações rivais.

\section{Capital social subdesenvolvido}

Vimos a participação dos líderes timorenses na tomada de decisões e o problema do diálogo político entre eles. E os cidadãos? A questão é importante, porque as sociedades com suficiente capital social construtivo são consideradas como sendo imunes a conflitos. É, portanto, de extrema importância que os peacebuilders tomem medidas concretas para construir, ou ajudar a construir, capital social em sociedades pós-conflito. O capital social é construtivo quando se esforça por evitar a violência, através de redes inclusivas com laços transversais. Por outro lado, o capital social pode também ter um papel negativo ao consolidar ligações entre grupos violentos (Cox, 2009).

A UNTAET deu apoio, tanto material como moral, a organizações não governamentais. Algumas ONG conhecidas, como a Yayasan HAK e a Fokupers, bem como algumas outras organizações, foram autorizadas a usar edifícios não ocupados como seus escritórios, e os doadores internacionais financiaram muitos projetos tanto de grupos com experiência como também de grupos novos. Assim, as ajudas internacionais à sociedade civil timorense complementaram a assistência humanitária, serviram de ponte entre as organizações internacionais e as pessoas, entre as quais havia um défice de

${ }_{14}$ A Audição Pública sobre o Conflito Político, 1974-1999, teve lugar entre 15 e 18 de dezembro de 2003 na sede de Díli da CAVR. Fui observador nessa ocasião, enquanto consultor de investigação da Comissão. 
comunicação, e contribuíram para a manutenção de um espaço público para o ativismo cívico, embora sobretudo no que se refere à juventude urbana. Mas é altamente duvidoso que estas ajudas tenham contribuído para a construção do capital social da sociedade mais ampla. O que deveria ter sido estabelecido eram as bases institucionais que incentivassem e apoiassem o ativismo cívico com uma perspetiva de longo prazo, de uma forma mais geral. Obviamente, como legado de uma ocupação estrangeira que não estava interessada em incentivar atividades cívicas espontâneas, havia muito poucas instalações que os cidadãos comuns pudessem usar para reuniões ou eventos de forma gratuita ou com um custo baixo. De facto, centros comunitários, centros de juventude, centros de mulheres e outras instalações públicas para atividades de grupo eram quase inexistentes. É de notar que, segundo os relatórios do Banco Mundial, a primeira parcela do Community Empowerment Project (CEP 1) financiou mais de 600 projetos subfinanciados, sendo $43 \%$ para salas de reunião comunitárias (Matsuno, 2008: 59). Isso mostra o quanto as pessoas necessitavam de instalações para reunir.

Os indonésios introduziram o seu sistema de bairro em Timor-Leste. De acordo com esse sistema, uma série de agregados familiares foram agrupados em RT (Rukun Tetangga) e depois uma série de RT num RW (Rukun Warga). Historicamente, o sistema remonta ao período de ocupação japonesa da Indonésia, entre 1942 a 1945, em que os militares ocupantes introduziram o sistema japonês de bairro (Tonarigumi). $\mathrm{Na}$ Indonésia da Nova Ordem, o sistema foi usado para organizar e mobilizar as pessoas ou para controlar o fluxo de pessoas e, apesar da intenção autoritária, há que reconhecer que, em certa medida, contribuiu para uma ordem comunitária. No entanto, no que se refere a Timor-Leste, é altamente duvidoso que tenha ajudado a construir capital social. Após o referendo, não só foi abandonado o sistema de RT e RW como também se abandonaram outras unidades sociais indonésias, incluindo grupos de donas de casa do programa PKK (Pembinaan Kesejabteraan Keluarga, capacitação para o bem-estar das famílias). No Timor-Leste pós-referendo, o sistema administrativo indonésio praticamente deixou de existir, e a anterior organização da resistência clandestina, principalmente o CNRT, preencheu essa lacuna, funcionando lado a lado com os líderes tradicionais e a igreja. De qualquer forma, havia muito poucas infraestruturas para atividades cívicas espontâneas.

O declínio do capital social construtivo numa Díli que se expandira rapidamente foi um fator que esteve na origem da crise de 2006. Com a deslocação de populações em grande escala, a reinstalação e o afluxo de migrantes após 1999, os subúrbios de Díli tornaram-se lugares onde os 
laços sociais eram muito fracos. Os extremos ocidental e oriental da cidade, como Aimutin, Comoro e Becora, eram particularmente vulneráveis ao incitamento e à mobilização. As pessoas viviam em conjunto em áreas densamente povoadas, mas contavam com redes de pessoas das mesmas origens e laços de família. Jovens com antecedentes semelhantes, desempregados e frustrados, reuniam-se em torno das artes marciais. Havia muito poucos laços transversais ou mecanismos comunitários inclusivos que reunissem as pessoas para resolverem os seus problemas.

\section{Conclusão}

A construção da democracia em Timor-Leste durante o período transitório das Nações Unidas esteve rodeada de condições difíceis. A própria ONU não tinha ainda formulado em pormenor a ajuda à democracia, o mandato da UNTAET não incluía explicitamente a construção da democracia e a UNTAET tinha de trabalhar sob pesadas restrições de tempo, orçamento e recursos humanos. Entretanto, o povo de Timor-Leste tinha tido muito pouca experiência de regime democrático, e as elites políticas estavam ainda obcecadas com a grave rivalidade que tinha raízes históricas no seu passado sombrio. O crucial diálogo político tinha desaparecido. Além disso, o longo domínio estrangeiro não permitira o desenvolvimento do ativismo cívico saudável, e o resultado foi a falta de uma infraestrutura básica para atividades cívicas espontâneas. As pressões para uma saída rápida privaram tanto a UNTAET como os timorenses do tempo necessário para discutir e resolver de forma eficaz os problemas de construção da democracia. Se assim não tivesse sido, os dois anos do período de transição pós-referendo teriam sido uma oportunidade preciosa para se estabelecerem as bases firmes de uma futura sociedade democrática. Mas perdeu-se essa oportunidade, e um resultado dessa falha foi a crise de 2006.

Pode extrair-se uma série de lições a partir da experiência de construção da democracia em Timor-Leste durante o período da UNTAET. Primeiro, a construção da democracia precisa de ser firmemente integrada na agenda de construção da paz, e deve ter um quadro claro e concebido de forma adequada a um determinado país. Não deve ser baseada em projetos e deve apoiar-se numa perspetiva de longo prazo. É especialmente importante aqui, de um ponto de vista da construção da paz pós-conflitos, o conhecimento da situação local, incluindo a história do conflito e as relações complexas dos respetivos atores. Quando as pessoas lutam pela identidade, a rivalidade e competição não são algo que se possa negociar. As dimensões ideológicas e psicológicas devem ser levadas em conta e tratadas no processo pós-conflito. A criação de instituições não é suficiente. 
Em segundo lugar, a construção da democracia não deve ser de cima para baixo e não deve considerar apenas as instituições democráticas no centro. Deve manter o equilíbrio entre o setor do Estado e a sociedade, entre Díli e os distritos, e entre zonas urbanas e zonas rurais. É necessário assegurar que são criados canais de baixo para cima. A construção institucional a nível comunitário deve ser uma prioridade.

Em terceiro lugar, a participação dos atores locais no projeto de construção da democracia é crucial. Deverá ser permitida não apenas a consulta, mas a mais genuína participação, porque, em última análise, são aqueles que devem assumir a responsabilidade pelo funcionamento da democracia no futuro. Deve ser-lhes dada a oportunidade de definir a agenda, negociar as regras e aprender a chegar a um consenso por consulta. A ONU deve ter a coragem suficiente para facilitar e supervisionar o processo.

Em quarto lugar, é preciso fomentar o capital social construtivo. Não se trata apenas de apoiar grupos de pessoas com as mesmas ideias, mas de promover laços transversais entre diferentes grupos.

A construção da democracia não deve ser entendida meramente como uma área de políticas planeada, implementada e avaliada exclusivamente por peacebuilders. Pelo contrário, deve ser entendida como um processo complexo no qual peacebuilders, elites políticas e sociedade civil interagem, tendo como objetivo comum criar um mecanismo mais inclusivo de tomada de decisões. As políticas e os programas de construção da democracia devem ser firmemente colocados neste contexto e concebidos para criar uma constante interação entre si. É errado pensar que os partidos políticos que venceram as eleições podem fazer o que quiserem, pelo facto de terem um "mandato" para governar. É isso mesmo que a ONU deve provar através das suas políticas e ações.

Tradução de João Paulo Galvão

Artigo recebido a 23.02.2014

Aprovado para publicação a 19.08.2014

\section{Referências bibliográficas}

Arnold, Matthew B. (2009), "Challenges Too Strong for the Nascent State of Timor-Leste”, Asian Survey, 49(3), 429-449.

Cogen, Marc; Brabandere, Eric de (2007), "Democratic Governance and Post-conflict Reconstruction", Leiden Journal of International Law, 20, 669-693.

Cox, Michaelene (org.) (2009), Social Capital and Peace-building: Creating and Resolving Conflict with Trust and Social Networks. London/New York: Routledge. 
Diamond, Larry (2005), "Lessons from Iraq”, Journal of Democracy, 16(1), 27-39.

Fukuyama, Francis (2006), "Dili in a Pickle", The American Interest, 22 de dezembro de 2006. Consultado pela última vez a 27.08.2014, em http://www.the-american-interest. com/articles/2006/12/22/dili-in-a-pickle/.

Grove, Natalie; Zen, Kiera; Bucar, Eurosia; Pereira, Luis Moniz Cardoso; Fernandes, Geovana; Amaral, Noemia (2007), Like Stepping Stones in the River: Youth Perspectives on the Crisis in Timor-Leste. Dili: Plan Timor-Leste.

ICG - International Crisis Group (2006), Resolving Timor-Leste's Crisis. Asia Report No. 120. Brussles: International Crisis Group, 10 de outubro.

Kingsbury, Damien (2007), “Timor-Leste: The Harsh Reality after Independence”, Southeast Asian Affairs 2007, 363-377.

Matsuno, Akihisa (2008), "The UN Transitional Administration and Democracy Building in Timor-Leste", in David Mearns (org.), Democratic Governance in Timor-Leste: Reconciling the Local and the National. Darwin: Charles Darwin University Press, 52-70.

Matsuno, Akihisa (2009), "Stability and Democracy in Post-Conflict East Timor", in Herbert Wulf (org.), Still Under Construction: Regional Organisations' Capacities for Conflict Prevention. INEF Report 97/2009. Institute for Development and Peace, University of Duisburg-Essen, 40-54.

Moxham, Ben (2008), "State-making and the Post-Conflict City: Integration in Dili, Disintegration in Timor-Leste", Working Paper, 32 - Cities and Fragile States, fevereiro. Crisis States Working Papers Series No. 2.

Pedersen, Jon; Arneberg, Marie (orgs.) (1999), Social and Economic Conditions in East Timor. International Conflict Resolution Program, School of International and Public Affairs, Columbia University, Estados Unidos/Fafo Institute of Applied Science, Noruega.

Power, Samantha (2008), Chasing the Flame: Sergio Vieira de Mello and the Fight to Save the World. London: Allen Lane/Penguin Press.

Richmond, Oliver P.; Franks, Jason (2008), "Liberal Peacebuilding in Timor-Leste: The Emperor's New Clothes?”, International Peacekeeping, 15(2), 185-200.

Scambary, James (2006), A Survey of Gangs and Youth Groups in Dili, Timor-Leste. A report commissioned by Australia's Agency for International Development. Australia's Agency for International Development.

Shoesmith, Dennis (2003), "Timor-Leste: Divided Leadership in a Semi-Presidential System", Asian Survey, 43(2), 231-252.

Siapno, Jaqueline (2006), “Timor-Leste. On a Path of Authoritarianism?”, Southeast Asian Affairs 2006, 325-342.

Suco Survey 2001 (2001), "Initial Analysis and Implications for Poverty Reduction”. East Timor Transitional Administration, Asian Development Bank, The World Bank and the United Nations Development Programme, outubro.

UNDP - United Nations Development Programme (2002), East Timor Human Development Report 2002. Dili: UNDP. 
$100 \mid$ Akihisa Matsuno

UNDP - United Nations Development Programme (2006), Timor-Leste Human Development Report 2006. Dili: UNDP.

United Nations (2006), Report of the United Nations Independent Special Commission of Inquiry for Timor-Leste, 2 de outubro de 2006, Geneva. 